\title{
Are Doctor Mothers the Superbeings? An Autoethnographic Reflection
}

\author{
Shivali Shamsher
}

\begin{abstract}
Doctor mothers have dual responsibility. In addition to the professional responsibility doctor mothers are home makers as well. They are responsible for patient care, administration, teaching, research, community outreach at the same time nursing their children, providing for their basic needs, household chores (cleaning, washing, cooking etc.) and most importantly being physically present for the tender loving care of their children in times of need. The journey of doctor women into motherhood is filled with various challenges of multiple roles with dual responsibility making them vulnerable to stress and burnout. Juggling successfully between the work life balance requires them to be Superbeings to keep stress and burnout at bay. The struggles and difficulties can be turned into hope and beautiful better life with the help of supportive spouse and family, understanding and cooperative colleagues, friendly working environment and mother friendly institutional policies. Good day-care facilities with trustworthy domestic help will be the cherry on the cake.
\end{abstract}

Keywords: Autoethnography, Burnout, Work-life balance.

SBV Journal of Basic, Clinical and Applied Health Science (2019): 10.5005/jp-journals-10082-02216

Women in Malaysia have outnumbered men in top professions like dentists, lawyers, accountants and doctors. However, the fairer sex still trails behind when it comes to holding decision making posts in top public listed companies (PLCs). ${ }^{1}$ This autoethnography tries to reason out this gap.

This article is a narrative, which is an attempt to validate my experiences with navigating multiple identities. I hope to illuminate others (professional mothers) who may correlate to my anecdote.

In today's world of cutthroat competition and professionalism, doctors are not limited to seeing patients and prescribing medicines; they are expected to do administrative work, teaching, community outreach, as well as research. They are continuously growing in their careers and are being assessed for their capability at each step. If one is not career oriented, she tends to be left out and the subordinate takes over. Somewhat making it even more difficult for female doctors. Female doctors are not exempted from the household responsibilities, which since ages automatically come under female's territory. Furthermore, once female doctors get married, they spontaneously become managers of the house. And if the blessings continue and they do well to manage all spheres of their life, they are promoted as mothers, increasing suddenly their responsibility to an altogether different level. They have their children all the time in their mind. At the same time they are expected to work wholeheartedly for the benefit of the patients ignoring their own personal needs.

Medicine has made it crystal clear that an expecting mother has special needs (physiological changes of pregnancy). ${ }^{2}$ As the age of the mother increases especially in medical careers so does the complications. Does the medical profession cater to these special needs of pregnant doctors? Do they get enough physical, mental and social support keeping in mind the drastic process they are going through or are they looked at as availers of medical/maternal leave?

Do doctors who are nursing mothers have the liberty to choose to continue breastfeeding after the maternal leave ends which is usually 2-3 months? Mostly not, because of pressure of professional workload, they are not allowed "personal time" though there are
Department of Anesthesia, Asian Institute of Medicine, Science and Technology, Bedong, Kedah Darul Aman, Malaysia

Corresponding Author: Shivali Shamsher, Department of Anesthesia, Asian Institute of Medicine, Science and Technology, Bedong, Kedah Darul Aman, Malaysia, Phone: +60 0126987687, e-mail: shivalibernard@gmail.com

How to cite this article: Shamsher S. Are Doctor Mothers the Superbeings? An Autoethnographic Reflection. J Basic Clin Appl Health Sci 2019;2(4):153-155.

Source of support: Nil

Conflict of interest: None

"Breast feeding rooms" in every hospital in accordance with the government policy supporting breastfeeding.

Doctor mothers leave their infants and children under someone else's care. "In times of emergency how fast can she make arrangements to reach back?" Questions like this do haunt every mother. Who does even think of providing her the assurance?

As the children start schooling, every mother wants their children to excel. Mothers try to make their children all-rounders, good in studies, sports, extracurricular activities as well as provide them emotional support whenever needed. Do doctor mothers have the luxury to be present for all of these?

Considering everything must go on hand in hand, patient care, administration, teaching, research, community outreach, nursing their children, proving for their basic needs, household chores (cleaning, washing, cooking etc.) most importantly being physically present for the tender loving care in times of need. All this at the cost of their own health and needs. Sometimes doctor mothers when they are on call have sick patients under their care, who are depending on them for their life, so they are unavailable to their own household for all practical purposes. Doctor mothers or for that matter any working mother is best described in one word as Superbeings or Supermoms. 
Every sector is taking about "burnout", the reasons and the management. ${ }^{3}$ These Superbeings are at high risk of developing burnout. A study conducted showed that more women surgeons had burnout than men surgeons. ${ }^{4}$ On the other hand it had been seen that patient treated by female doctors have less complication rates, better outcomes, less mortality and readmissions., ${ }^{5,6}$ All the more reason that female doctors should be encouraged and motivated time and again to continue to get their involvement and services.

Based on personal experiences, I (anesthesiologist and mother) would like to offer solutions to think and live with rather than sterile facts and findings to nip the problem in the bud to prevent burnout and drop out among this group, making life better and enjoyable.

Starting from choosing this profession. During counseling or while exploring the career options, the females should be introduced to these aspects as well. The whole picture should be painted, not just the professional aspects as the profession is one aspect of a persons' life and not the whole life. They must choose what is going to define them. WHO defines health as a state of physical, mental and social well-being and not merely the absence of a disease. They should be given the insight into all the spheres of life with doctor as profession.

I was blessed to be born to doctor parents (general practitioners). My father worked full time but mother probably following folkways sacrificed to be part- time. Though both were equally qualified and talented, mother opted for this because she had the additional responsibility of the house and children or I must say for better "work-life balance", in today's world. Overlooking the full time/ part-time carrier option, but having a very clear good family life concept, I chose to be a doctor myself.

To put it, I wanted to be a successful doctor (like my father) and an excellent homemaker (like my mother). I was naïve to the predicament of work life balance. My life as well as my career seemed to be under my control, so much so that I could keep our wedding at hold till the completion of my postgraduation. Thereafter things became more practical as I shifted to another country post marriage with more than 3 years of postgraduate experience in anesthesiology. In my previous institution I had established myself but in the new place I had to prove my worth and start from scratch at the same time juggling with the new role as a homemaker in altogether new environment.

According to a study, female physicians reported work-life balance as a significant concern, with the goal of achieving work-life balance often impacting their career choices in a study. ${ }^{7}$

During my initial years of struggle adapting to a new workplace and new roles in life, what helped me to keep everything together was the wonderful professional boss (mother of four children), understanding colleges, my parents by Skype calls and last but not the least caring husband. They provided all the support required to help me keep my professional as well as family life in harmony, taking special care of my needs during pregnancy. I strongly believe that loving care, safe and non-hostile working environment provided to all the expecting doctors can help them give their hundred per cent during pregnancy as well.

In accordance with the international women's day (IWD) 2019's theme being "Balance for better", everyone is required to appreciate the multiple roles that women play and consider how everyone can help this vulnerable group balance their multiple roles for the better. ${ }^{1}$
After my confinement period finished, I was back at work and was expected to resume all my previous job scopes. Everything was supposed to be the same, me as well as my work. But what was not the same was that I was a mother now. My baby was constantly in my thoughts. Till now postpartum depression was only a chapter in books, I saw it becoming a reality. My baby, who was part of me for the past few months, was now going to be under the care of a maid alone at home. I had lost all control. I felt helpless. I experienced what is known as burnout. I was on the verge of desperation when my mother and my sister decided to take turns (comply with visa rules) to come and stay with us and take care of the baby. Though I was not physically present with the baby all the time I had the assurance that he is in safe hands. I am lucky to have such a caring family but not everyone is.

The higher authorities should consider the needs, responsibilities and commitments of these special doctors and make a day care in every hospital where their children are in safe hands and the doctor mothers can work with the peace of mind and give their hundred percent. Nursing rooms are present in most of the healthcare facilities as most of the governments enforce breast feeding but we do not have the data of their use by the female doctors themselves.

As time passed by, I got used to the on-call post call schedule and by God's grace had a good help (full-time maid). Though there were times, accidents happened, which are part of the child's growing up process I suppose. A good colleague support at work made it possible for me to reach in time. My husband took care of the baby all the nights I did on calls. I believe not a single night call I did would have been possible without the support of my husband.

Every doctor mother has her own story. If doctor mothers have their support group where they can share their experiences, the new members can gain a lot. Sharing humor, science and life experience to help each other along in the quest for work-life balance and happiness amidst all. It can be a platform to discuss strategies, secrets and solutions.

There were times when both the working parents were unavailable to the child. I made sure I gave clear instructions to the domestic help (maid) taking care of the child. For example, after the child finishes the homework, he can watch TV. At the same time entrusting the maid with responsibilities which at times is not easy.

I also believe that doctor mothers would also benefit if they have feasible domestic help which is affordable and trustworthy. The higher authorities can help in this area also, by encouraging organizations to develop such companies for providing reliable and trustworthy domestic help services.

Post call off meaning the off day after continuous duty is given to the doctors to rest but for mothers it is the golden opportunity to spend time with the child and to do the pending chores. Doctor mothers hardly get time for themselves to relax, making them more vulnerable to burnout.

"All work and no play makes Jack a dull boy", last but not the least doctor mothers should be given some time officially for spending for themselves, doing things which they once cherished like painting, dancing, movies, physical exercise, yoga, sports but never have the time to do so.

There can be no other better platform than mother's day when we can appreciate doctor mothers as super moms and provide them the gift of their own time and facilitate them to spend few hours for themselves. 


\section{SUMMARY}

Doctor mothers need to be "Superbeings" which makes them vulnerable to burnout. Recognizing their potential and maximizing their benefits, at the same time keeping them motivated is the need of the hour. We need to promote doctor mother support group, day care facilities especially for doctor mothers' children in the hospital premises and domestic help services among others.

\section{Acknowledgements}

I would like to acknowledge my Dean for the idea, encouragement, guidance and help in writing this autoethnography. This article would not have been a reality without the love, support and care of my parents and sisters and most importantly my loving and caring husband and understanding son. I also would like to acknowledge my bosses, colleagues and juniors of my previous workplace and my current Head of the Department of Anesthesiology, for the support.

\section{References}

1. Yuen $M$, Women outnumber men in fields such as medicine, dentistry, law and accountancy. The STAR Online. 2019. Available at https:// www.thestar.com.my/news/nation/2019/03/08/more-femaleprofessionals-in-msia-women-outnumber-men-in-fields-such-asmedicine-dentistry-law-and-a/\#GkpBTB8MzmgVy5vB.99, (accessed at 4th August 2019).

2. Priya SP, Catherine NP, Heli T, Alexandre M. Physiological changes in pregnancy. Cardiovasc J Afr 2016;27(2):89-94. DOI: 10.5830/CVJA2016-021.

3. Balch CM, Freischlag JA, Shanafelt TD. Stress and burnout among surgeons: understanding and managing the syndrome and avoiding the adverse consequences. Arch Surg 2009;144(4):371-376. DOI: 10.1001/archsurg.2008.575.

4. Dyrbye LN, Shanafelt TD, Balch CM, Satele D, Sloan J, Freischlag J. Relationship between work-home conflicts and burnout among american surgeons: a comparison by sex. Arch Surg 2011;146(2): 211-217. DOI: 10.1001/archsurg.2010.310.

5. Tsugawa Y, Jena AB, Figueroa JF, Orav EJ, Blumenthal DM, Jha AK Comparison of hospital mortality and readmission rates for medicare patients treated by male vs female physicians. JAMA Intern Med 2017;177(2):206-213. DOI: 10.1001/jamainternmed.2016.7875.

6. Christopher JDW, Bheeshma R, Natalie C, Robert KN, Allan SD, Raj S. Comparison of postoperative outcomes among patients treated by male and female surgeons: a population based matched cohort study. BMJ 2017;359:j4366. DOI: 10.1136/bmj.j4366.

7. Yulia TG, Roni P. Female physicians and the work-family conflict. IMAJ 2016;18(5):261-266. 